\title{
Prática docente no Ensino Superior: a formação pedagógica como mobilizadora de mudança
}

Kelen dos Santos Junges*

Marilda Aparecida Behrens**

\section{Resumo}

Entende-se que a formação pedagógica permite ao professor universitário a olhar para sua prática pedagógica, interpretá-la e recriá-la, tornando-a também uma fonte de aprendizagem numa perspectiva de mudança e de inovação. Para tanto, optou-se neste texto apresentar uma das questóes que compuseram uma pesquisa de tese e tem como objetivo analisar a formaçáo pedagógica como mobilizadora de mudança da prática docente no ensino superior. A pesquisa adotou como metodologia a pesquisaação em um programa de formação pedagógica com professores universitários de uma instituição de ensino superior pública municipal, denominado de Grupo Docência em Reflexão (GDR). Como instrumento de coleta de dados foi utilizado uma entrevista semiestruturada com dez dos professores participantes do processo formativo. A categorização dos dados coletados revelou que as mudanças na prática pedagógica dos professores entrevistados, a partir das atividades do GDR, incidiram, especialmente, na percepção do que é ser professor universitário, no relacionamento com os alunos, na organização didática das aulas, na avaliação do processo de ensino e aprendizagem, na reflexão sobre a prática e nas dificuldades encontradas por eles ao implementar uma mudança em sua prática pedagógica. Assim, considerou-se que uma proposta de formação pedagógica orientada e partilhada dos professores universitários, baseada em açóes concretas e inserida numa perspectiva reflexiva, além de uma aprendizagem docente mais profunda e duradoura, mobiliza mudanças na prática pedagógica desses professores, incitando uma prática inovadora.

Palavras-chave: Professor Universitário. Formação Pedagógica. Prática Pedagógica..

\footnotetext{
* Doutora em Educação pela Pontifícia Universidade Católica do Paraná (PUC/PR). Professora do Curso de Pedagogia da Universidade Estadual do Paraná (Unespar), campus União da Vitória, PR.

** Doutora em Educação pela Pontifícia Universidade Católica do Paraná (PUC/PR). Professora do Curso de Pedagogia e da Pós-Graduaçáo em Educação na Pontifícia Universidade Católica do Paraná (PUC/PR).
} 


\section{Introdução}

Diante das mudanças na sociedade e na educação provocadas pelo avanço da ciência, é consenso entre diversos autores que investigam a formação pedagógica do professor universitário, como Cunha (2007b, 2010), Pimenta e Anastasiou (2002), Behrens (2009) e Bolzan (2008), que as universidades ainda não se alertaram para a necessidade urgente de oferecer processos contínuos de qualificaçáo de professores para atuar na docência da educaçáo superior. A grande maioria dos docentes são bacharéis e, em geral, nunca frequentaram uma formaçáo pedagógica para atuar como professores na universidade $\mathrm{e}$ nas faculdades. Alguns docentes que atuam na educaçáo superior optam por mestrados e doutorados em educação, ou seja, o nível stricto sensu, para buscar tal formação, mas, embora necessária, não tem sido suficiente para propor uma pedagogia universitária adequada às exigências atuais da Sociedade e da Educação. Outra constataçáo preocupante refere-se a realidade da universidade, pois os professores universitários titulados, em especial, no stricto sensu, normalmente, passam a priorizar a pesquisa e não o ensino.

A docência universitária exige que, além de conhecimentos sobre a área específica de formação, o professor também atue sobre fundamentos pedagógicos do processo de ensino-aprendizagem, aliados aos saberes de sua experiência e de sua produção científica. Nesse sentido, acredita-se que uma formação, voltada especialmente à prática pedagógica dos professores, torna-se, então, desafio essencial a ser transposto no ensino superior.

A formação pedagógica permite ao professor universitário olhar para sua prática pedagógica, interpretá-la e recriá-la, tornando-a também uma fonte de aprendizagem numa perspectiva de mudança e de inovação.

Neste texto são apresentadas contribuiçóes levantadas numa tese de doutorado, realizada numa instituição de ensino superior pública municipal um programa de formação pedagógica, realizado por um ano letivo, composto por 32 professores universitários. Adotou-se como metodologia de investigação a pesquisa-ação que contou com vários instrumentos de coleta de dados, mas optouse por apresentar neste texto os dados levantados numa entrevista semiestruturada, com dez dos professores que participaram de todo o processo formativo.

Cabe ressaltar que as mudanças observadas e destacadas neste artigo são açôes ou concepçôes que indiquem uma alteração na prática pedagógica dos professores entrevistados (segundo os próprios professores), a partir de sua 
participação na formação pedagógica continuada, de modo a exprimirem uma apropriação de conceitos e açôes diferenciadas das que vinham realizando em seu exercício docente.

Considerou-se que uma proposta de formação pedagógica orientada e partilhada dos professores universitários, baseada em ações concretas e inserida numa perspectiva reflexiva, além de uma aprendizagem docente mais profunda e duradoura, mobiliza mudanças na prática pedagógica desses professores, incitando uma prática inovadora.

\section{O lugar da formação pedagógica na docência universitária}

O professor pode ser entendido como o "profissional do conhecimento", como sugere Marcelo García e Vaillant (2009). O domínio do conhecimento científico, o saber, tem sido o que distingue e legitima a profissão docente, pois, segundo os autores, o que absolutamente justifica o trabalho do professor é o seu compromisso com a transposição desse conhecimento em aprendizagens significativas aos alunos, tornando-se um "profissional do ensino". Para manter esse compromisso, é imprescindível que os professores sintam-se compelidos a aprofundar e ampliar suas competências profissionais e pessoais.

Esse compromisso com a transposição de que tratam os autores e os conhecimentos necessários à docência compóem o conhecimento pedagógico que se torna elemento chave na pedagogia universitária. Para Bolzan (2008, p. 105), o conhecimento pedagógico é "um conceito base que se refere a um conhecimento amplo construído pelo professor, em seu processo formativo, implicando o domínio do saber fazer, bem como do saber teórico e conceitual e suas relaçóes".

Numa visão conservadora, o pressuposto era de que o domínio do conteúdo seria suficiente para o exercício da docência no ensino superior, ou seja, os saberes pedagógicos eram considerados irrelevantes na constituição e formação do professor universitário. Libâneo (2011) pontua que esse é um problema recorrente no ensino superior. Porém, a expansão do desse nível de ensino e a diversidade de seus alunos, a emergência de renovar o paradigma da ciência e da educaçáo, em especial, com a proposição da complexidade (MORIN, 2002), a nova visão ou o paradigma inovador exige o conhecimento do todo, no qual o professor compreenda: o contexto no qual ensina, a quem ensina (os alunos), como se ensina e que reconheça a si mesmo como pessoa e profissional. 
$\mathrm{Na}$ universidade, os professores que possuem uma atividade profissional liberal e estáo inseridos no mercado de trabalho, atuando na área específica na qual lecionam e dedicam-se parcial e paralelamente à docência, são valorizados por sua competência e êxito nessa profissão como administradores, arquitetos, entre outros.

No caso de professores universitários que se dedicam inteiramente à docência, a carreira acadêmica, geralmente, é valorizada e enaltecida muito mais pelas publicaçóes que realiza do que por seu desempenho em sala de aula. Nas duas situaçóes a competência pedagógica fica em segundo plano. Autores como Almeida e Pimenta (2011), Behrens (2003), Bolzan e Isaia (2006), Cunha (2006, 2007a), Cunha e Broilo (2008) e Corrêa et al. (2011) constatam tal situação nas universidades brasileiras.

O docente universitário, então, despende maior dedicação e tempo de estudo às atividades de pesquisa do que às atividades inerentes ao ensino, incluindo sua formação na área pedagógica. É comum professores universitários se identificarem socialmente, mais no campo científico (como advogados, arquitetos, médicos etc.), do que como docentes (como professor de). Por isso, as atividades acadêmicas que realizam (os livros que leem; os cursos/ eventos que frequentam; os artigos que produzem) estão mais relacionadas à sua formação inicial como profissionais bacharéis e liberais do que com a docência propriamente dita.

Nesse sentido, as açôes de formação pedagógica, como explica Zabalza (2004), precisam ser baseadas tanto nas necessidades de desenvolvimento individuais do professor como nas necessidades institucionais; necessitam integrar a motivação intrínseca do professor em participar de processos formativos com o reconhecimento externo como a avaliaçáo institucional e a valorização na carreira docente. $\mathrm{O}$ autor ainda pontua que a docência exige uma preparação específica como qualquer outra profissão.

A partir dessas disposiçóes, Nóvoa (2009) recomenda fatores importantes para alicerçar programas de formação de professores:

- a formação de professores precisa articular teoria e prática, a partir da análise de situaçóes concretas do cotidiano escolar, a procura de um conhecimento pertinente na reelaboraçáo desse conhecimento, traduzindo um processo de inovação;

- é relevante que a formação de professores passe para "dentro da formaçáo", isto é, ser conduzida e planejada pelos próprios 
professores, de forma que os professores principiantes aprendam com os professores mais experientes;

- a formação de professores necessita valorizar o trabalho em equipe, pois a reflexão e o trabalho coletivo transformam-se em conhecimento profissional, instigando processos de mudança e práticas concretas de intervenção.

- a formação precisa incentivar os professores a darem visibilidade social ao seu trabalho, a aprenderem a se comunicarem com o público, "a ter uma voz pública, a conquistar a sociedade para o trabalho educativo, comunicar para fora da escola" (NÓVOA, 2009, p. 43).

Para se colocarem em prática essas recomendaçóes, além do compromisso institucional com a formação pedagógica de seu quadro docente, é importante que os próprios professores percebam os processos formativos como algo que lhes é importante e que contribui para sua prática pedagógica, e que, por isso, necessitam ser contínuos. Para se dedicar a sua formação pedagógica não precisa se desligar de suas pesquisas, nem do exercício de uma profissão paralela, ao contrário pode e precisa realizar as duas atividades em conjunto.

Em geral, as universidades já começam a perceber que açôes pontuais e uniformes de formação pedagógica como cursos de curta duração, oficinas e palestras esporádicas para um grande número de professores têm o seu valor, pois pode gerar um clima de motivação ou esclarecer determinados assuntos ou temas aos professores, além de terem baixo custo e de mais fácil organização. Porém, por estarem alheias às reais necessidades formativas dos professores e náo terem uma continuidade, não favorecem um efeito efetivo na prática docente. Conforme Behrens (2007), esses eventos podem ser considerados como fase inicial de um processo, mas não como único subsídio para a formaçáo do professor universitário.

É fundamental oferecer projetos de formação pedagógica, em longo prazo, mais abrangentes e também que sejam coordenados por profissionais de dentro da própria instituição, para evitar a instabilidade e a descontinuidade do processo, pois a "[...] tendência ao status quo é forte o bastante para neutralizar um tipo de proposta que surge esporadicamente e que tenha responsabilidades incertas na instituição" (ZABALZA, 2004, p. 161).

Nessa afirmação o autor opóe-se a uma ação de formação não planejada e alheia a uma missão institucional. Uma proposta de formação requer 
flexibilidade e precisa iniciar a partir dos sujeitos envolvidos, mas isso não significa que não seja estruturada, sistematizada, refletida e inserida em um contexto organizacional. A instituiçấo universitária deve ter clareza de seus objetivos a respeito da formação de seus professores, bem como atender às necessidades destes.

Nesse caso, a formação pedagógica dos professores universitários é concebida, não como um rol de iniciativas fragmentadas e esporádicas das quais os docentes normalmente são obrigados a participar, com um caráter de treinamento, reciclagem ou capacitação, "[...] mas como um sistema, consagrado institucionalmente, de que todos os docentes participem como pensamos ser de seu direito e de seu dever, enquanto profissionais do ensino" (ESTEVES, 2010, p. 60).

Para tanto, as açóes de formação mais duradouras, em longo prazo, do ponto de vista de Zabalza (2004), tais como formação continuada, grupos de estudo, modalidades de pesquisa-ação, entre outros, costumam ter um "status" menor do que os grandes congressos e eventos, mas são muito mais eficientes na provocação de uma mudança nas práticas docentes.

Essas ações, por terem um sentido de continuidade e estarem ligadas aos interesses dos professores, podem proporcionar a eles um espaço de reflexão sobre seu exercício profissional na universidade, levando-os a tomarem consciência de que lecionar no ensino superior é uma atividade que exige preparação e que prescinde a improvisação.

O espaço reflexivo é entendido aqui como a alavanca para as transformaçóes pedagógicas, uma vez que leva os professores a perceberem que o "ensinar" náo é um processo "natural", tal como fazem ao simplesmente imitar modelos de professores, a partir de suas representaçóes como alunos, como uma fase de pré-formação anunciada por Formosinho e Machado (2009).

Interferir nessa "naturalização" da docência na universidade, na visão de Cunha (2006, p. 259), não prescinde de uma reflexão sistematizada, baseada na desconstrução e reconstrução da experiência, pois "os sujeitos professores só alteram suas práticas quando são capazes de refletir sobre si e sobre sua formação". A especificidade da formação pedagógica é refletir sobre a própria prática docente, na perspectiva de uma formaçáo continuada.

Por isso, adota-se, neste trabalho, o conceito de formação pedagógica continuada como um espaço contínuo e duradouro, no qual o professor é sujeito ativo, descobrindo a si mesmo como profissional, que organiza suas 
ideias, fundamenta, investiga e reconstrói sua prática e teoria, numa perspectiva reflexiva, sem perder de vista seus propósitos educacionais. Pretende-se que a formação continuada seja alicerçada nas necessidades, nas dúvidas, nas perspectivas dos próprios docentes, para que se envolvam e gerem mudança em sua prática pedagógica.

Cabe ressaltar, entáo, que a experiência ou a prática por si mesma não se reverte em aprendizagem. Um professor com anos de experiência não significa que seja um bom professor do ponto de vista pedagógico. Se sua prática não é uma prática refletida, observada, continuamente revista a partir dos interesses dos alunos, durante os anos letivos podem ser apenas uma repetição de ações e acúmulo de tempo que serve simplesmente para a progressão na carreira.

É evidente também que ser um especialista em determinada área do saber e exímio pesquisador não torna alguém um professor competente. A pesquisa, assim como a docência, exigem qualidades e saberes específicos, como salientam Pimenta e Anastasiou (2002). Além disso, às vezes, a área e os conteúdos da pesquisa do professor não são os mesmos do seu ensino e a tentativa de ligação entre eles (entre o que se pesquisa e o que se ensina) pode desviar os conteúdos do ensino do programa, ou seja, da proposta inicial da disciplina.

Em geral, a formação para a pesquisa acontece nos cursos e programas de pós-graduação stricto sensu. A formação para a docência, mais especificamente, a formação pedagógica, é que ainda precisa encontrar seu lugar no ensino superior. Para Behrens (2007), os cursos de Mestrado em Educação, em geral, não apresentam formaçáo suficiente para o docente atuar em sala de aula, porém cabe refletir que os profissionais das diversas áreas do conhecimento buscam os Programas stricto sensu em Educação, para melhorar sua atuação docente universitária, no entanto, quando ingressam no Programa, encontram linhas de pesquisa que investigam referenciais importantes na formação do pesquisador, mas nem sempre para qualificar sua formação pedagógica.

Ensinar exige saberes, habilidades que podem ser adquiridas e/ou potencializadas por meio de um processo formativo pedagógico que pode suprir essa carência deixada pela formação inicial ou pelo programa de pósgraduação. Sendo assim, alguns conhecimentos e práticas são fundamentais na formação pedagógica do professor universitário, e são conhecimentos de cunho pedagógico, que, no caso do ensino superior, são buscados para além da ciência ensinada, pois são comuns no ensino de qualquer área do conhecimento, avançando para além do domínio da especialidade científica. 
Acrescenta-se à competência pedagógica do professor universitário o compromisso com a aprendizagem dos alunos, entendendo o ensino e a aprendizagem como faces interdependentes. Quando o ensino e a aprendizagem não caminham lado a lado, os professores preocupam-se em ensinar e não se os alunos aprenderam. Consideram que, se os alunos não aprenderam, a culpa é inteiramente deles, porque não se dedicaram o suficiente. Segundo Zabalza (2004), nessa dicotomia os alunos deparam-se abandonados à própria sorte e dependentes quase exclusivamente de sua própria capacidade de trabalho.

Acreditando que o ensino superior objetiva preparar futuros profissionais, cidadãos para atuar na sociedade, com vistas à sua transformação, Leite (2006) alerta que os professores universitários necessitam refletir sobre sua ação pedagógica, sobre os conhecimentos pertinentes à sua área e sobre a constituição dos currículos, incluindo valores sociais e éticos.

Alguns pontos que podem servir como referências para uma docência universitária com uma visão de integração do ensino e da aprendizagem são apresentados por Zabalza (2004). Um primeiro ponto é transformar a ideia da aprendizagem contínua em conteúdo e em propósito do ensino, incentivando a produção de conhecimento em uma aprendizagem significativa. $\mathrm{O}$ ponto de referência seguinte é que o professor universitário precisa repensar a sua disciplina, a partir da perspectiva dos estudantes, no que lhes seria mais importante, mais útil, mais compreensível, entre outros. Outro ponto de referência apresentado pelo autor refere-se à ampliação que o professor universitário necessita fazer de seus conhecimentos a respeito do modo de aprendizagem dos alunos, compreendendo a fase de desenvolvimento na qual se encontram e que possuem modos de perceber o mundo e os conteúdos diferentes dos seus. De acordo com Zabalza (2004, p. 153), “[...] uma boa formação sobre os processos de ensino-aprendizagem servirá para elucidar e dar sentido à ação docente, contribuindo, assim, para sua melhora". A formação pedagógica, nesse sentido, é concebida como algo que qualifica o exercício das funçôes docentes.

No ensino superior, como salientam Corrêa et al. (2011), não existe, a princípio, uma formação inicial própria ao exercício da docência universitária, mas as instituiçóes precisam propor investimento nas açóes de formação continuada no âmbito pedagógico, com vistas ao desenvolvimento profissional.

A esse respeito, Pimenta e Anastasiou (2002) relacionam alguns aspectos a serem considerados na elaboração de uma proposta de formação pedagógica 
continuada de professores universitários. O primeiro deles é o conhecimento da realidade institucional que compóe um diagnóstico do contexto em questão, que norteia os conteúdos e a organização da proposta de formação. O segundo aspecto apresentado pelas autoras é a abrangência, que indica que uma proposta de formação precisa de um envolvimento do coletivo do corpo docente, com o apoio institucional, pois, como denota Esteves (2010, p. 57), "[...] se o professor não se vir e for visto como aquele que planifica, coordena, facilita, modera, monitoriza e aconselha, mais do que como aquele que transmite, nenhuma inovação significativa ocorrerá a este nível". Outro elemento a ser considerado numa formação pedagógica é o tempo: a duração de uma proposta de formação corresponde aos objetivos, etapas, encaminhamentos e à realidade institucional.

Para que a formação pedagógica se consolide é necessário que a instituição ofereça condições para a efetivação de mudanças produzidas e sugeridas pelos docentes, sendo um aspecto importante, como explicam Pimenta e Anastasiou (2002). Como o objetivo da formaçáo é a melhoria/modificação da prática pedagógica, é essencial que os docentes, ao se colocarem nesse processo, contem com o apoio institucional.

A esse respeito, Fernandes, Bastos e Selbach (2010, p. 133, grifo do autor) pontuam que é preciso configurar a formação pedagógica como um "construto teórico-prático marcado pela intencionalidade de um projeto de ação transformadora e emancipatória que tem na sua dimensão coletiva e na responsabilidade institucional uma possibilidade de concretude". Esse construto teórico-prático trata de basear a formação pedagógica nos saberes da prática e da teoria que surgem a partir da reflexão de uma e de outra, colocando uma em confronto com a outra, no sentido de compreendê-las, contextualizá-las e recriá-las. Nesse sentido, a reflexáo passa a ser um elemento essencial da formaçáo pedagógica continuada, alinhada a um processo de construçáo da profissionalidade e do desenvolvimento profissional.

Nesse caminho, Imbernón (2011) expõe que uma formação específica para a docência universitária, ajudará os professores a: auxiliar no desenvolvimento e difusão do conhecimento na comunidade, questionando sua legitimidade social e originalidade; desenvolver uma formação crítica e transformadora; estar disponível para mudanças; promover sua autoformação; envolver-se em temas sociais, culturais e políticos; manter a articulação entre teoria e prática docente.

Entende-se que essas indicaçôes feitas pelos autores, a partir das exigências da contemporaneidade e da pedagogia universitária, confluem para uma 
perspectiva inovadora ${ }^{2}$ da docência, na qual o docente universitário é chamado a ser um investigador da própria prática, da sua realidade e de seus alunos, mediando açôes que instiguem a dúvida, a formulação de perguntas e a busca de respostas em parceria com os alunos, de forma criativa e reflexiva, tornandose uma ponte entre eles e o conhecimento.

No contexto tecnológico da sociedade atual, com diversas fontes distribuidoras de informação e conhecimento, o professor universitário precisa saber mediar esses conhecimentos disponíveis aos alunos, de forma a torná-los profissionais competentes, mas, também, cidadãos conscientes. Isso exige do professor universitário um trabalho coletivo, com seus pares, que ultrapasse as fronteiras de sua disciplina, que reconheça o contexto do seu ensino, da sua produção e o de seus alunos.

Torna-se claro, então, que o professor no ensino superior, além de ter a responsabilidade de formar profissionais, também tem o compromisso de contribuir para formação de "pessoas" que atuarão na sociedade, não somente numa profissão, mas como empreendedores sociais, cidadãos, membros de famílias que também interferirão na formação de outras pessoas e na construção de uma sociedade em constante movimento.

Nessa concepção inovadora, a aula não é vista apenas como uma sequência de situaçóes prescritas, lineares e previsíveis, como pontua Franco (2011). Ao contrário, a aula é um espaço de construção do saber, de mediação do conhecimento, a partir da contextualização e da problematização da realidade, com a participação efetiva de professor e alunos, numa troca mútua, com momentos de produção individual e coletiva. Portanto, conforme a autora, a prática docente inovadora na universidade não se confunde com um acúmulo acrítico de procedimentos metodológicos ou técnicos, ao contrário, é uma prática refletida, séria, consciente e responsável.

Sendo assim, a proposta desta formação pedagógica pretendeu agregar esses pontos citados pelos autores, considerando e gerando um processo de formação pedagógica continuada, relacionando conteúdos e atividades, a partir dos interesses dos próprios professores, de forma a fornecer fundamentos para o "refletir" sobre a docência, o saber-fazer docente e a melhor compreensão desta "concepçáo inovadora" exigida para o desenvolvimento de uma prática relevante que auxilie os professores e os alunos a produzirem conhecimentos. 


\section{Caminhos metodológicos no processo de pesquisa}

Para este artigo, adotou-se como viés metodológico a pesquisa-ação que contou com quatro fases, conforme a orientação de Dionne (2007). A primeira fase foi a de realizar um diagnóstico inicial por meio de um questionário estruturado, a fim de identificar os interesses e expectativas dos professores de uma instituição pública municipal, locus da pesquisa, em participar de um programa de formação pedagógica continuada.

A segunda fase tratou de organizar a proposta formativa e de constituir o grupo de professores participantes. Sendo assim, o programa foi constituído por um grupo de 32 professores universitários, com perfil diversificado em relação à área de formação, tempo de docência no ensino superior e idade. A maioria dos professores participantes possui curso de Bacharelado, é iniciante na carreira docente no ensino superior e também atua em suas profissóes específicas paralelamente à docência.

A proposta de formação pedagógica foi organizada numa perspectiva reflexiva de formação continuada, inerente ao processo de pesquisa-ação como expóe Elliott $(2005,2010)$, por isso o Programa foi denominado de Grupo Docência em Reflexão (GDR).

Acreditou-se que é por meio da reflexão que o professor pode identificar, organizar e nomear os significados que se atribui a inúmeros fatos vividos, mediante os quais se pode reconstruir as diversas compreensóes que se têm sobre si mesmo e sobre a docência universitária. O espaço contínuo criado por uma formação pedagógica num processo de pesquisa-ação pode colaborar para esse exercício reflexivo e ampliar as perspectivas pelas quais uma experiência pode ser estudada, levantando questóes e problemas a serem compreendidos e solucionados coletivamente.

Sendo assim, buscou-se promover uma formaçáo continuada, no intuito de criar um momento pensado para e com os professores, em que pudessem se reunir e refletir sobre suas experiências, discutir sobre as concepções que permeiam sua atuação, entre outros, de forma processual e dinâmica, podendo assim "[...] permitir ao professor questionar-se porque ensina deste ou daquele jeito, entender o porquê e como se tornou o professor que é e, especialmente, perceber que não é um ser acabado, mas um sujeito histórico, que está em constante constituição" (JUNGES, 2006, p. 139). 
A terceira fase da pesquisa-ação foi a realização da formação pedagógica propriamente dita que ocorreu durante um ano letivo, aos sábados pela manhã, uma vez ao mês, totalizando dez encontros, intercalados com atividades online. Cada encontro presencial teve um eixo temático para discussão, sendo eles: novos paradigmas na docência universitária; o aluno universitário; relação professor e aluno; ser professor universitário; saberes docentes; ética profissional docente e a Pedagogia de Paulo Freire; ser professor reflexivo e a avaliação do processo de ensino e aprendizagem. Os temas trabalhados foram sugeridos pelos próprios professores a partir da realizaçấo de diagnóstico por meio de um questionário.

A dinamizaçáo dos encontros contou com atividades diversificadas, tais como estudo de textos, dinâmicas de grupo, relatos e troca de experiências, palestras, análise de filmes, privilegiando a dimensão pessoal de cada professor e a dimensão coletiva da ação docente, tendo sempre como eixo norteador a reflexão, a prática pedagógica dos participantes e a perspectiva inovadora na docência. Nos intervalos dos encontros presenciais, os participantes eram convidados a cumprir desafios, que englobaram leitura de textos, observação da sala de aula, desenvolvimento de atividades junto aos alunos, fóruns online, troca de materiais, e-mails e reflexóes das próprias experiências e trajetórias docentes.

A quarta fase da pesquisa-ação constituiu-se da avaliação do processo formativo que foi realizado durante todo o processo, mas mereceu atenção constante das pesquisadoras e dos professores participantes, individual e coletivamente, efetivada nas reflexóes realizadas pelo grupo. Ao final do programa formativo os professores participantes foram desafiados, por meio de uma entrevista semiestruturada, a analisarem sua prática pedagógica inicial (antes da formação pedagógica) e atual (depois da formação pedagógica). Foram selecionados para as entrevistas somente os professores participantes que estiveram presentes em todos os encontros, num total de dez. Dos dez professores entrevistados, sujeitos da pesquisa ora apresentada, oito professores são Bacharéis; sete professores são formados em cursos de Mestrado ou Doutorado e três em cursos de Especialização; cinco professores têm de 26 a 30 anos e os demais acima de 35 anos; sete professores possuem mais de quatro anos de docência no Ensino Superior e três professores têm menos de quatro anos de experiência docente nesse nível de ensino.

As entrevistas realizadas com os professores participantes nessa fase foram compostas por um roteiro semiestruturado de perguntas que incluiu questóes sobre a satisfaçáo dos docentes com o processo formativo, as aprendizagens e 
as mudanças realizadas em sua prática a partir do GDR. Neste texto, devido ao seu objetivo, serão destacados apenas os dados relacionados às mudanças na prática pedagógica dos participantes entrevistados.

Cabe ressaltar que as mudanças observadas e destacadas neste artigo são ações ou concepçóes que caracterizem uma perspectiva inovadora da docência como já exposto anteriormente, que indiquem uma alteração na prática pedagógica dos professores entrevistados (segundo os próprios professores), a partir de sua participação na formação pedagógica continuada, de modo a exprimirem uma apropriação de conceitos e açôes diferenciadas das que vinham realizando em seu exercício docente.

As entrevistas foram gravadas e posteriormente transcritas para análise. Como forma de preservar a identidade dos sujeitos, cada professor entrevistado recebeu a sigla "P" e um número de 1 a 10 para sua nominação no decorrer do texto.

\section{A formação pedagógica e a mudança da prática docente dos participantes}

A categorização dos dados coletados nas entrevistas revelou que as mudanças na prática pedagógica dos professores entrevistados, a partir das atividades do GDR, incidiram, especialmente, na percepção do que é ser professor universitário, no relacionamento com os alunos, na organização didática das aulas, na avaliação do processo de ensino e aprendizagem, na reflexão sobre a prática e nas dificuldades encontradas por eles ao implementar uma mudança em sua prática pedagógica.

Os dados assinalam mudanças que estáo ocorrendo efetivamente no seu exercício docente, conforme suas vivências, aprendizagens e conhecimentos construídos no GDR. Tais mudanças refletem a repercussáo da formação pedagógica continuada, numa tentativa de incorporar uma prática mais inovadora no Ensino Superior. De acordo com os depoimentos, uma repercussão gerada pela formação pedagógica foi na percepção do que é ser professor universitário no contexto atual, como relata o Professor 2: "O que mudou foi a 'visäo', você vê de uma forma diferente, você vê o 'ser professor' de uma forma diferente. Você vê os alunos de uma forma diferente" (P2).

Os depoimentos sugerem que anteriormente à participaçáo nos encontros formativos, os professores possuíam uma visão conservadora da 
docência. Acreditavam que ser professor era apenas "repassar", com uma boa oratória, os conteúdos de determinada disciplina, ou seja, o ensinar não estava, necessariamente, ligado à aprendizagem. Aprender era uma "obrigação" e responsabilidade exclusiva do aluno.

Desse modo, os Encontros do GDR oportunizaram aos participantes perceberem que sua prática é permeada e influenciada por suas concepçóes de educação, de aprendizagem, entre outras. Permitiu que os professores envolvidos se sentissem mais comprometidos com a docência, que se compreendessem e observassem com mais completude, como profissionais do ensino, como afirmam os professores envolvidos:

Agora eu me sinto mais professora, antes era mais Engenheira. (P8).

Hoje eu me considero um 'professor mais profissional'. Antes eu praticava a docência e tinha bons resultados, aceitação, mas eu vejo que era de uma forma mais empírica, mais experimental. Eu pegava os conteúdos e passava para os alunos do jeito que eu achava que tinha que ser, dava uns exercícios. Mas agora isso já começa a acontecer do jeito que as pessoas [educadores, pesquisadores] dizem que tem que ser e não do jeito que eu acho que tem que ser. Os autores falam que tem que ser dessa forma, que tem que ser contextualizado, que tem ser trabalhada a questão prática junto com embasamento teórico e isso eu tive conhecimento a partir de cursos e dos Encontros. (P10).

Esse efeito da formação nas concepções dos professores foi imprescindível, de acordo com Ferreira (2009), para provocar mudanças também nas suas práticas docentes. Se os professores não mudam sua maneira de conceber e compreender a educação, o ensino e a aprendizagem, não são capazes de mudar sua maneira de agir em relaçáo a eles. As concepçóes que os professores têm sobre o ensino influenciam diretamente a maneira como agem sobre ele.

A repercussão de um processo formativo, na visão de Ferreira (2009), pode ocorrer nos diversos domínios que compóem a profissionalidade docente, na construção e elaboraçáo de saberes sejam eles pedagógicos, curriculares, disciplinares, sejam relacionados a atitudes e valores pessoais. 
$\mathrm{Na}$ contribuição do $\mathrm{P} 8$, formado inicialmente num curso na área de engenharia, pode-se entender que o conhecimento pedagógico trabalhado e apreendido na formaçâo continuada lhe permitiu identificar-se mais com a docência e é esse o conhecimento, como explica Trindade ${ }^{3}$, que difere o professor dos demais profissionais. O saber ensinar é algo particular da profissionalidade docente, que confere ao profissional uma característica própria, uma identidade. Todas as profissões possuem um corpus de saberes que lhe são singulares, mas, também, saber ensinar esses conteúdos de forma que sejam realmente aprendidos, pertence à docência.

Ainda, nota-se no relato do entrevistado P10 que, ao ingressar na docência no ensino superior, o profissional proveniente de um curso de Bacharelado, como é o caso desse Professor participante. lança mão, em sala de aula, das experiências que vivenciou como aluno e de suas representaçóes do que é ser professor, como explicam Anastasiou (2011), Bolzan e Isaia (2006), Cunha (2006, 2010), Corrêa et al. (2011), Pimenta e Anastasiou (2002). Com o tempo, Anastasiou (2011, p. 65) comenta que o professor percebe que "lhe são exigidos saberes, comportamentos e atitudes que muitas vezes não foram objeto de estudo e sistematizaçấo em seus percursos anteriores".

Assim, o engajamento em experiências de formação continuada específicas para a docência torna-se um meio de desconstruir crenças anteriores, para adquirir novos saberes e conhecimentos do campo educacional, ou seja, para construir uma profissionalidade para atuar como docente universitário. Nessa perspectiva, a formação continuada, num primeiro momento, passa a ser, na verdade, a formação inicial para a docência do professor universitário.

Sobre o relacionamento com os alunos, os professores entrevistados perceberam que, ao estabelecer uma aproximação dos alunos, estes passaram a demonstrar mais interesse, a aula fluía com mais tranquilidade e, aos poucos, conquistavam a sua confiança e o seu comprometimento. Com esse entendimento, modificaram sua maneira de agir e se relacionar com os discentes, diminuindo a distância criada entre um e outro:

Bem, me aproximei mais dos alunos, mudei algumas metodologias, as quais facilitaram o entendimento deles porque, talvez, en estivesse bem mais voltada para a teoria $e$ ai o aluno fica sentado, enquanto estou falando, estäo só ouvindo e é como se só eu estivesse atuando, agora passaram 
a interagir mais, houve uma aproximação não só pessoal, mas professor e aluno. (P8).

Eu acho que uma coisa que eu percebi, que depois do curso eu consegui a me relacionar melhor com os alunos. Eu tinha muita insegurança por causa mesmo da idade e de ser recém-formada. Então, eu entrava na sala e não conseguia delimitar bem meu papel como professora e acho que essa insegurança, afastava ainda mais os alunos, porque abria espaço para que eles criticassem, esse tipo de inconveniência. E com o curso deu pra refletir a respeito de você ter contato com o aluno, tentar conquistá-lo, de trazê-lo pra perto de você ao invés de afastá-lo. (P7).

O estreitamento da relação entre os professores e seus alunos está associado a uma mudança na organização didática adotada pelos professores, em sua prática pedagógica, para trabalhar os conteúdos. O exemplo dado na organização e estruturação dos Encontros, baseado numa perspectiva inovadora reflexiva na literatura estudada, permitiu que os professores percebessem que a sua prática também poderia ser modificada, melhorada, inovada, rompendo com as formas tradicionais de ensinar e aprender. Os relatos dos entrevistados indicam as mudanças que fizeram, especialmente, nas suas estratégias de ensino:

A cada sábado que nós nos encontrávamos eu sempre tentava modificar alguma coisa, até porque nós tínhamos os desafios e eu fui tentando adaptar, modificar. Porque às vezes a gente acha que está indo no caminho certo, mas não estamos. A gente tem que ter também essa visão crítica do nosso trabalho. O que mudou mais foi minha metodologia. (P4).

Então eu levava o flime e passava inteiro. Esse ano eu levei o mesmo filme, mas selecionei as cenas, fiz um roteiro do que eles tinham que observar, trabalhei a teoria, a gente discutiu então teve uma outra sequência. Porque vi que passar o filme inteiro fica muito cansativo, são 4 aulas... Então assim fica mais dinâmico, eles discutem, acham bacana e eles interagem. (P5).

Então, toda essa reflexão me ajudou a procurar a fazer uma aula melhor, uma aula que o aluno goste. Em momento 
algum escutei algum um aluno falando pra mim assim: 'professora, de novo esses power point?' Eu não tive esse comentário esse semestre! (P6).

Os depoimentos deixam claras as mudanças efetivadas pelos professores em suas práticas em relação à metodologia adotada e à organização da aula, essas alterações relatadas são evidências de melhoria, de inovação, como anuncia Behrens (2009, 2006). Para Moran (2006, p. 28-29), os professores avançam em direção a uma prática inovadora quando conseguem "[...] adaptar os programas previstos às necessidades dos alunos, criando conexóes com o cotidiano, com o inesperado, se transformarmos a sala de aula em uma comunidade de investigação".

Para tanto, uma prática inovadora também exige que os professores universitários conheçam o projeto da instituição, de seu curso e de sua disciplina, numa visão de interligaçáo, requer um trabalho coletivo de todo o quadro de gestores e docentes, de maneira a transpor os limites das disciplinas divididas cartesianamente, atuando de forma interdisciplinar, com métodos globalizados, trabalhando com seminários, projetos, conteúdos contextualizados, com uma avaliação formativa, por portfólio, entre outros. Um dos entrevistados demonstra uma visão inovadora quando comenta que:

Essa relação que antes, talvez, eu não tivesse muito, esta ideia da interdisciplinaridade, que é você trabalhar, tentar conversar com outros professores do curso o quê que cada um está trabalhando, o que cada um pode utilizar dentro da matéria um do outro, ou colaborar [...] Porque, às vezes, o aluno precisa entender isso, que não é tudo separado, é tudo junto, é uma coisa só, é uma formação. Então cada conhecimento vem para completar um ao outro, não para ficar separado, dividido, então isso é importante que os alunos saibam também. E se você não fala isso, talvez passe despercebido por eles, não associando uma coisa com a outra. Então, o professor é muito importante para tentar auxiliar o máximo os alunos, mostrar e conversar bastante. (P1).

Os professores entrevistados entenderam que uma aula baseada no contexto e nas exigências educacionais, que buscam a qualidade do processo 
ensino aprendizagem, precisa ser conectada com a vida do aluno, por meio de caminhos diferenciados como a experiência, a exposição, o diálogo, a imagem, o uso de recursos tecnológicos, a pesquisa, entre outros, utilizando-se da linguagem oral, escrita e digital, envolvendo-o em todo o processo de produção do conhecimento.

O foco na aprendizagem numa prática inovadora, justamente, reclama uma metodologia que incentive a participação dos alunos como descobridores e produtores de conhecimento numa atitude de curiosidade, criticidade e comprometimento; que promova o desenvolvimento de habilidades cognitivas, emocionais, sociais, humanas e profissionais em parceria com os professores. Dos professores, por sua vez, exige-se planejamento, a abertura ao diálogo, a disponibilidade para ser um mediador, um pesquisador da própria prática que se vê como alguém em constante formação.

Essa mudança vem ao encontro da proposta de Rodríguez (2002), de que o contato com novos procedimentos e estratégias e a aprendizagem de novas maneiras de ensinar estimula o professor a reformular sua atuação e a ingressar em um novo campo do conhecimento.

Acredita-se que ao vivenciar novas experiências no processo de formação pedagógica continuada, os professores não somente perceberam que existe uma variedade de recursos e atividades que podem ser aproveitadas e que são possíveis de serem realizadas, bem como se sentiram mais seguros para utilizá-las em sala de aula, à medida que alguns já as tinham experienciado.

Da mesma forma que na metodologia que utilizavam, os sujeitos observaram que o "modelo" de avaliação que realizavam não atendia ao que se exige de uma prática inovadora, isto é, na medida em que alteravam as estratégias de ensino também precisavam modificar a forma de avaliação, percebendo que ambas são elementos de um mesmo processo: do ensino-aprendizagem. Sendo assim, perceberam que precisariam efetivar alteraçóes em suas práticas avaliativas, e foi o que fizeram, como se pode notar nos relatos a seguir:

Agora eu faço questôes objetivas, questóes subjetivas e são três ou quatro avaliaçóes no bimestre. Então eu faço projetos, eu faço pesquisa, provas, dinâmicas. (P5).

Passei a refletir mais, talvez o ensino que eu passava era bastante imposto: 'isso é assim por causa disso' e talvez eu não desse espaço pra eles questionarem [...] Hoje isso mudou. 
O resultado acho que é melhor, pois estou dando aula para facilitar, para mostrar o porquê das coisas, então, a meu ver, náo tem sentido os alunos reprovarem, eu não ganho nada com isso. Eu estou me esforçando para que eles aprendam [...]. (P8).

Acho que a forma de avaliar. Porque tinha algumas avaliaçōes que eu fazia muito teórica e você acaba percebendo que o aluno, às vezes, é melhor na prática. (P9).

Percebe-se nos relatos que os sujeitos adquiriram uma nova forma de encarar o processo avaliativo, não veem mais como uma determinação legal ou como um instrumento unilateral, mas como um meio de avaliação de todo um processo de ensino e de aprendizagem que pode proporcionar também uma autoavaliação docente e uma autoavaliação discente.

Nos depoimentos de vários dos entrevistados, percebe-se evidências de que as mudanças efetivadas pelos professores ocasionaram mudanças também nos alunos, pois, como explica Guskey (2005), os resultados discentes náo são identificados apenas por seu desempenho acadêmico nas avaliaçôes, mas também por seu comportamento, suas atitudes, sua frequência e participação nas aulas, seu interesse pela aprendizagem. Alguns dos Professores observaram esses resultados, conforme denotam em seus comentários:

Teve uma dinâmica do curso que apliquei e os alunos amaram, a do GVGO. Era uma turma quieta, mas eles falaram bastante. Se eu tivesse passado aquele conteído, teria sido um caos. Porque vi que eles aprenderam muito mais, porque eles tiveram que ler sobre o tema, tiveram que se reunir. E parece que quando eles estão mais próximos, no caso do grupo de verbalização, eles se sentem mais a vontade e participam mais. Eles sabiam que todos tinham que falar ali do grupo [GV] e outros estavam anotando, observando [GO], depois foi o inverso, e aquele grupo que observou primeiro se saiu muito melhor. Depois disso eu pedi que eles escrevessem um texto do que eles haviam entendido do assunto e eles me disseram quando me entregaram o material de como tinha sido fácil escrever sobre o assunto depois que eles tinham falado que tinham escutado os colegas. Então foi uma técnica muito boa, bem útil. (P6). 
Lembro do caso de um aluno assim, que ele vai muito mal quando écálculo, por exemplo, que era uma disciplina que eu estava trabalhando, mesmo na parte teórica ele ia mal. Eeu pedi para eles apresentarem um trabalho sobre determinado tema e ele foi muito bem nesse trabalho. Ele se destacou na sala. Até comentei no final, na sala, que as avaliaçóes com ele deveriam ser orais, porque ele se dá muito melhor. (P9).

Observa-se que os entrevistados também notaram que os alunos nem sempre aprendem da mesma maneira e que cada um tem seu ritmo próprio e particular. Por isso, sentiram a necessidade de variar técnicas e metodologias para ampliar e melhorar o alcance de seu ensino, para motivar e influenciar o desempenho dos alunos, como mostra o depoimento do participante P9, acima. Na visão de Guskey (2002), a identificação de resultados significativos na aprendizagem ou no comportamento discente é a alavanca para mudanças nas práticas docentes. Entende-se que evidências positivas no desempenho dos alunos, geralmente, são precedidas de mudanças realizadas nas atitudes e crenças dos professores.

Nas entrevistas, os participantes também indicaram algumas dificuldades que enfrentaram, ao implementar mudanças em sua prática pedagógica para atuar de forma inovadora, a partir do proposto no programa de formação pedagógica.

Entre as dificuldades, notou-se que ao mesmo tempo em que vários dos entrevistados apontaram melhorias nas atitudes e aprendizagem dos alunos, alguns dos participantes indicaram, como uma das dificuldades, certa resistência destes à mudança implementada, à aceitação de uma nova forma de trabalho pedagógico, como relatam os Professores 8,7 e 5:

Na maioria das turmas funciona, mas quando tem uma turma muito extensa fica um pouco mais complicado porque infelizmente ainda tem alguns que querem se aproveitar da situação só pra passar e não colaboram. (P8).

Então, por exemplo, dos paradigmas, tenho tentado muito levar coisas diferentes, outras metodologias, mas tenho sentido muito que os alunos não estão preparados. Então, as dificuldades que encontrei fazendo isso: 'A h a professora hoje não quer dar aula', ou de repente vira tudo uma bagunça e você acaba perdendo o controle, não sai da forma como você 
tinha planejado [...] Então, acho que ainda falta um pouco mais da parte dos alunos de entrarem nesse novo paradigma, de também se comprometerem com o aprendizado. (P7).

Tais depoimentos assinalam que a mudança não é algo fácil, e que não depende somente da vontade do professor, mas de outros elementos como os alunos, que também são participantes na sala de aula. Como explica Esteves (2010), os discentes presentes, hoje, no ensino superior possuem uma escolaridade anterior mais diversificada, com interesses e projetos de vida variados, com múltiplos perfis culturais e sociais e com um futuro profissional no mundo do trabalho incerto, mesmo com o "diploma" universitário. Isso desafia o trabalho do professor, exigindo-lhe maior atenção, flexibilidade e preparação.

Também, muitas vezes, a resistência dos alunos provém de sua formação anterior, enraizada numa visão conservadora, bem como pode estar associada à acomodação, ao receio do desconhecido ou à predileção pelo caminho mais "fácil", que já está trilhado, pois, como coloca o entrevistado P5 acima, inovar e produzir conhecimento exige maior dedicaçáo do professor, mas também dos alunos.

Para uma prática inovadora, a participação do aluno é primordial, pois alunos interessados e comprometidos estimulam o trabalho do professor, favorecem a comunicação dialógica, a descoberta e a aprendizagem significativa. Para tanto, é necessário ao professor persistir na mudança e realizá-la de forma gradativa e processual. Moran (2006) explica que é importante o professor mostrar ao aluno as vantagens e benefícios desse novo processo, a parceria que estabelecerão e os resultados que poderão ser conquistados para a sua aprendizagem e formação profissional.

Outra dificuldade mencionada por um dos Professores entrevistados foi a organização do próprio sistema de ensino universitário, que embora se proponha a realizar e exige um ensino de qualidade, com ideias criativas e inovadoras, ainda está engessado por uma estruturação burocrática e reguladora, como se percebe no depoimento do Professor 9:

Eu acho que, de uma maneira geral, todas as instituiçôes vão limitar de alguma forma, porque no final do bimestre, por exemplo, você vai ter que ter uma nota para avaliar o aluno e normalmente você náo consegue fazer, numa turma muito grande, como é o caso de Engenharia Civil, fazer uma avaliação individual de cada aluno. Então, você acaba 
fazendo uma avaliação que fique mais fácil pra você naquele periodo de tempo. (P9).

Relacionada a essa limitação, cinco dos participantes entrevistados citaram a falta de tempo como uma dificuldade para investirem mais na formação pedagógica. Explicaram que a quantidade de aulas que precisam preparar, de avaliaçóes que precisam corrigir (pelo excessivo número de alunos em salas de aula), as pesquisas que precisam desenvolver e os compromissos com a profissão exercida além da docência exigem muita dedicação e um tempo maior que, muitas vezes, poderiam dedicar-se à pedagogia universitária. Por isso, por vezes justificam que não conseguiram realizar as leituras indicadas ou os desafios propostos nos Encontros, com a profundidade de que gostariam.

Essa questão limitadora do "tempo" é algo que poderia ser revisto pelas instituiçóes de ensino superior como sugerem os professores entrevistados, propiciando melhores condiçōes para que os professores pudessem também dedicar-se a estudos e processos formativos referentes ao ensino, sem ter que abdicar de outras atividades. Assim feito, as instituiçóes poderiam exigir com mais propriedade e equilíbrio a qualidade de ensino dos professores e a sua produção acadêmica.

Entende-se que professores e instituiçóes de ensino superior precisam vencer as limitações e dificuldades que obstruem ações formativas e inovadoras juntos, cada qual assumindo sua parcela de responsabilidade. $\mathrm{Na}$ visão de Rodríguez (2002), a promoção de uma educação de qualidade está relacionada a uma boa formação dos professores e o seu desenvolvimento profissional, à organização do trabalho e à instituição. É um trabalho de investimento e empenho conjunto, no qual todas as partes obtêm benefícios, afinal, como acentua Guskey (2002), as instituiçóes não podem ser melhores do que os professores e gestores que nelas trabalham.

Uma formação dos professores que seja significativa depende da valorização que é dada pela Instituição e pelos docentes aos saberes pedagógicos. Acredita-se que a valorização do conhecimento pedagógico e sua repercussão, na prática, acontecem quando o professor percebe que aquele conhecimento e aquela nova açáo podem the trazer vantagens, melhorando e ampliando a abrangência de seu ensino, e contribuindo para o desempenho dos alunos, como se pode constatar na fala do Professor 6: 


$$
\text { de mudança }
$$

Mudei a partir do momento que comecei a perceber que isso estaria me ajudando também no ensino. Porque no momento que você cria um vínculo, não aquele vínculo carinhoso, mas aquele vinculo em que o aluno percebe que o professor se importa com ele, faz a diferença. Eu percebi que a partir do momento que eu mudei, que passei a conversar mais com o aluno, a me interessar um pouco mais: 'O que você está fazendo? Isso te ajuda?', comecei a conversar um pouco mais com eles, o relacionamento ajudou bastante, eu percebi a diferença na prática. E isso mudou a partir dos encontros. [...] Eu sempre aguardei bastante os encontros porque eu percebi a importância deles. (P6).

Esse depoimento do participante P6 indica que é essencial que o conhecimento pedagógico seja apresentado ao docente como um instrumento útil, que facilitará e melhorará seu desempenho, que estará a seu serviço para o ensino dos conhecimentos científicos e que terá um efeito positivo nos resultados dos alunos, como salienta Guskey (2002). A partir dessa visão, o conhecimento pedagógico passa a receber mais atenção e relevância pelos professores do ensino superior.

Por isso um projeto de formaçáo precisa partir das necessidades dos professores, porém é importante que os formadores também tenham uma capacidade de observação que lhes permitam oferecer aos formandos conhecimentos e instrumentos que não sabem que são necessários, mas que, se utilizados, melhorarão a qualidade de suas aulas, pois, como explica Rodrigues (2006), muitas vezes os professores sentem necessidade apenas daquilo que sabem que existe, mas que ainda não possuem. Para a autora, os professores não têm como sentir necessidade de algo que não sabem que existe.

Nesses termos, o programa de formação pode proporcionar o contato com novos saberes, ferramentas, conceitos e fazer aflorar projetos que, depois de percebidos como úteis, se tornarão necessidades e influenciarão diretamente na prática pedagógica dos professores num processo contínuo de reconstrução, como relatam os Professores 2 e 8 :

[...] que quando você não tem conhecimento de uma coisa porque você vai pensar nela? Porque você não sabe que ela existe. A partir da hora que as pessoas colocam na tua frente, que é explicado que ela tem objetivo, para que ela serve, 
lógico que tudo tem um porquê [...]. Porque a gente tem lá dentro um cantinho, mais precisa ser estimulado. Eu sempre digo, habilidades você tem, mas precisa ser estimulada. Você às vezes pensa, mas não sabe como colocar em prática e, assim, como te falei, estou engatinhando. Então é uma forma de eu conseguir trazer isso para fora, de eu aperfeiçoar, de melhorar, de eu ser criativa. (P2).

Porque se ninguém sinaliza, se ninguém mostra que isso está daquela ou dessa forma, a pessoa sempre vai achar que está certa, porque só tem aquele horizonte, entâo se é oferecido para aquelas pessoas situaçóes que isso é assim etc. ela consegue refletir, mas se não é oferecida, é como se a pessoa sempre estivesse certa e não necessariamente, ai fica difícil enxergar outras coisas. (P8).

Sendo assim, a presente pesquisa permitiu perceber que o professor deixa transparecer em sua prática a sua trajetória, as suas crenças e convicçóes. Isso significa que, se não houver mudança de concepção, de postura, de entendimento dos processos educacionais que é proporcionado pela reflexão, não haverá modificação na prática dos professores universitários. Por exemplo, os professores podem inserir a tecnologia em sala de aula, que é uma ferramenta considerada "atual", mas se não tiverem mudado a forma de encarar o ensinar e o aprender para uma perspectiva inovadora, usaráo a tecnologia apenas para continuarem a reproduzir o conhecimento, como faziam com o giz ou com as transparências, mantendo uma visão conservadora.

\section{Considerações finais}

No Ensino Superior, comumente constata-se que o professor, especialmente aquele proveniente de um curso de Bacharelado, náo possui dificuldade no domínio de sua especialidade de formação e de atuaçáo no mundo do trabalho, porém urge por uma formação pedagógica que o prepare para atuar em sala de aula, que é, para ele, um novo campo de atuaçáo profissional, para o qual não foi habilitado.

Partindo dessa premissa, a proposta deste estudo compreendeu um processo de formação pedagógica, tendo como base a reflexão dos professores sobre suas experiências e as teorias que as fundamentam, pretendendo apontar 


$$
\text { de mudança }
$$

possibilidades e influenciar a prática pedagógica desses professores, num sentido inovador, como delineado no texto.

Dessa forma, a presente pesquisa não pretendeu traçar generalizaçóes a respeito da formação pedagógica de professores universitários, mas estudar e intervir em uma dada realidade, pois como salienta Barbier (2007, p. 119), "toda pesquisa-ação é singular e define-se por uma situação precisa concernente a um lugar, a pessoas, a um tempo, a práticas e a valores sociais e esperança de uma mudança possível".

Assim, com o objetivo de analisar a formação pedagógica como via mobilizadora para mudança da prática docente no ensino superior, e o recorte desta questão de investigaçáo da tese apresentado, permite afirmar que os achados da pesquisa revelam que uma proposta de formação pedagógica orientada e partilhada dos professores universitários, baseada em açóes concretas e inserida numa perspectiva reflexiva, além de uma aprendizagem docente mais profunda e duradoura, mobiliza mudanças na prática pedagógica desses professores, incitando uma prática inovadora.

Sem dúvida, a organização dos Encontros do GDR, levando os professores a pensarem sobre o que fazem e como fazem, confrontando com a literatura e com as experiências dos colegas, foi o diferencial para que pudessem realizar aprendizagens significativas e mudanças em seu exercício docente, como mostraram os Sujeitos participantes.

As mudanças apontadas pelos professores entrevistados, no sentido de buscarem diferentes e novas práticas, ficam explícitas ao relatarem seu novo "olhar" do processo de ensino e aprendizagem; quando comentam sobre o estreitamento da sua relaçáo profissional com os alunos; ao adotarem recursos didáticos diferenciados e reorganizarem suas aulas e a forma de avaliação a partir dos interesses e necessidades dos alunos. Também, ao se depararem com algumas dificuldades como a resistência dos alunos a algo novo, a estruturação do sistema universitário e a falta de tempo, perceberam que a docência não é uma atividade solitária e desvinculada da realidade, mas que envolve outros agentes, bem como fatores reguladores.

Portanto, o estudo realizado permite ressaltar que as mudanças, as transformações, o conhecimento de novas concepções ou ainda, as repercussões de uma formação pedagógica continuada na sala de aula universitária, por menores e mais pontuais que sejam, têm sua validade e relevância, mas são 
processuais, acontecem gradativamente, num ir e vir constante, e que, por isso, é necessário se pensar em uma pedagogia universitária, com vistas a uma formação docente permanente.

Nesse sentido, a docência universitária numa perspectiva inovadora, que entende o professor como agente social, o aluno como cidadão crítico e a instituição educativa como campo de produção do conhecimento, exige um comprometimento com a aprendizagem, ao longo de toda a vida, num movimento dinâmico de mudança, de ação-reflexão-ação e de articulação da teoria e da prática.

Conforme Zabalza (2004), participar de um curso de formação não torna um professor universitário mais competente, mas lhe fornece instrumentos para isso. Considera-se que a simples participação do professor do ensino superior numa ação formativa não garante a sua repercussão em sala de aula, porém o seu envolvimento num processo de formação pedagógica continuada que o leve a refletir, a ter consciência de sua ação e de sua trajetória, a ampliar sua percepção e conceitos sobre a docência, que proporciona a percepção da possibilidade de melhoria em seu ensino, tem grandes chances de gerar mudanças em sua prática e de contribuir para o seu desenvolvimento profissional como as que se pôde constatar nesta pesquisa.

\section{Notas}

${ }^{1} \mathrm{O}$ presente texto apresenta contribuiçóes levantadas na pesquisa de tese (JUNGES, 2013) que tinha como objetivo principal analisar a contribuição da formaçáo pedagógica, numa perspectiva reflexiva, para o desenvolvimento profissional de docentes do Ensino Superior e as possíveis repercussões dessa formação para uma prática pedagógica inovadora dos professores de uma instituiçáo pública municipal de União da Vitória, PR.

${ }^{2} \mathrm{O}$ fundamento teórico do sentido de "prática inovadora" firmado no texto provém do Paradigma Inovador ou Paradigma da Complexidade (BEHRENS, 2006; CAPRA, 2010; MORIN, 2002) e refere-se a uma nova concepção de ciência e de mundo trazidas pelas inovaçóes tecnológicas e pela Sociedade do Conhecimento, que altera a forma de se encarar a também a educação. Nessa concepção, o professor é entendido como um agente social, o aluno como cidadão crítico e a instituição 
educativa como campo de produção de conhecimento na busca da transformação sociedade.

3 TRINDADE, Rui. Entrevista concedida a Kelen dos Santos Junges, Porto, 10 maio 2011.

\section{REFERÊNCIAS}

ALMEIDA, Maria Isabel de; PIMENTA, Selma Garrido. A construção da pedagogia universitária no âmbito da Universidade de São Paulo. In: PIMENTA, Selma Garrido; ALMEIDA, Maria Isabel de (Org.). Pedagogia universitária: caminhos para a formação de professores. São Paulo: Cortez, 2011. p. 19-43.

ANASTASIOU, Léa das Graças Camargos. Processos formativos de docentes universitários: aspectos teóricos e práticos. In: PIMENTA, Selma Garrido; ALMEIDA, Maria Isabel de (Org.). Pedagogia universitária: caminhos para a formação de professores. São Paulo: Cortez, 2011. p. 44-74.

BARBIER, René. A pesquisa-ação. Brasília: Liber Livro, 2007. (Série Pesquisa).

BEHRENS, Marilda Aparecida. A formação pedagógica e os desafios no mundo moderno. In: MASETTO, Marcos (Org.). Docência na Universidade. 6. ed. Campinas, SP: Papirus, 2003. p. 57-68.

BEHRENS, Marilda Aparecida. Projetos de aprendizagem colaborativa num paradigma emergente. In: MORAN, José Manuel; MASETTO, Marcos T.; BEHRENS, Marilda Aparecida. Novas tecnologias e mediação pedagógica. 12. ed. Campinas, SP: Papirus, 2006. p. 67-132.

BEHRENS, Marilda Aparecida. O paradigma da complexidade na formaçáo e no desenvolvimento profissional de professores universitários. Educação, Porto Alegre, ano 30, n. 3, p. 439-455, set./dez. 2007. Disponível em: <http://revistaseletronicas.pucrs.br/fo/ojs/index.php/faced/article/ view/2742/2089>. Acesso em: 10 jul. 2010.

BEHRENS, Marilda Aparecida. O paradigma emergente e a prática pedagógica. 3. ed. Petrópolis, RJ: Vozes, 2009. 
BOLZAN, Doris Pires Vargas. Pedagogia universitária e processos formativos: a construção do conhecimento pedagógico compartilhado. In: ENCONTRO NACIONAL DE DIDÁTICA E PRÁTICAS DE ENSINO, 14., 2008, Porto Alegre. Anais... Porto Alegre: PUC/RS, 2008. p. 102-120.

BOLZAN, Doris Pires Vargas; ISAIA, Silvia Maria de A. Aprendizagem docente na educação superior: construções e tessituras da professoralidade. Educação, Porto Alegre, v. 29, n. 3, p. 489-501, set./dez. 2006. Disponível em: <http://revistaseletronicas.pucrs.br/ojs/index.php/faced/issue/view/44>. Acesso em: 29 out. 2010.

CAPRA, Fritjof. A teia da vida: uma nova compreensão científica dos sistemas vivos. 5. ed. São Paulo: Cultrix, 2010.

CORRÊA, Adriana Kátia et al. Formação pedagógica do professor universitário: reflexôes a partir de uma experiência. In: PIMENTA, Selma Garrido; ALMEIDA, Maria Isabel de (Org.). Pedagogia universitária: caminhos para a formação de professores. São Paulo: Cortez, 2011. p. 75100.

CUNHA, Maria Isabel da. Docência na universidade, cultura e avaliação institucional: saberes silenciados em questão. Revista Brasileira de Educação, Rio de Janeiro, v. 11, n. 32, p. 258-271, maio/ago. 2006.

CUNHA, Maria Isabel da. O lugar da formação do professor universitário: a condição profissional em questão. In: CUNHA, Maria Isabel da (Org.). Reflexōes e práticas em pedagogia universitária. Campinas, SP: Papirus, 2007a.

CUNHA, Maria Isabel da (Org.). Reflexóes e práticas em pedagogia universitária. Campinas, SP: Papirus, 2007b.

CUNHA, Maria Isabel da. Os conceitos de espaço, lugar e território nos processos analíticos da formação dos docentes universitários. In: CUNHA, Maria Isabel da (Org.). Trajetórias e lugares de formação da docência universitária: da perspectiva individual ao espaço institucional. Araraquara, SP: Junqueira \& Marin, 2010. p. 45-57.

CUNHA, Maria Isabel da; BROILO, Cecília Luiza. Pedagogia universitária: desafios da produção do conhecimento. In: CUNHA, Maria Isabel da; BROILO, Cecília Luiza (Org.). Pedagogia universitária e produção de conhecimento. Porto Alegre: EDIPUCRS, 2008. p. 29-35. 


$$
\text { de mudança }
$$

DIONNE, Hugues. A pesquisa-ação para o desenvolvimento local. Brasília: Liber Livro Editora, 2007. (Série Pesquisa).

ESTEVES, Manuela. Sentidos da inovação pedagógica no ensino superior. In: LEITE, Carlinda (Org.). Sentidos da Pedagogia no Ensino Superior. Porto: CIIE/Livpsiv, 2010. p. 45-61.

FERNANDES, Cleoni Maria Barboza; BASTOS, Amélia Rota Borges de; SELBACH, Paula Trindade da Silva. Estudo três: cursos de disciplinas de formação pedagógica do professor universitário: movimentos em aberto. In: CUNHA, Maria Isabel da (Org.). Trajetórias e Lugares de formação da docência universitária: da perspectiva individual ao espaço institucional. Araraquara, SP: Junqueira \& Marin, 2010. p. 125-145.

FERREIRA, Fernando Ilídio. A formação e seus efeitos: do modelo escolar à formação em contexto. In: FORMOSINHO, João (Coord.). Formação de professores: aprendizagem profissional e acção docente. Porto: Porto Editora, 2009. p. 329-344.

FORMOSINHO, João; MACHADO, Joaquim. Professores na escola de massas: novos papéis, nova profissionalidade. In: FORMOSINHO, João (Coord.). Formação de professores: aprendizagem profissional e acção docente. Porto: Porto Editora, 2009. p. 143-164.

FRANCO, Maria Amélia Santoro. Prática docente universitária e a construção coletiva de conhecimentos: possibilidade de transformaçóes no processo ensino-aprendizagem. In: PIMENTA, Selma Garrido; ALMEIDA, Maria Isabel de (Org.). Pedagogia universitária: caminhos para a formação de professores. São Paulo: Cortez, 2011. p. 159-187.

GUSKEY, Thomas R. Professional development and teacher change. Teachers and teaching: theory and practice, London, v. 8, n. 3/4, p. 381-391, 2002. Disponível em: $<$ http://translate.google.com.br/translate?hl=pt-BR\&sl $=$ en $\& \mathrm{tl}=\mathrm{pt} \& \mathrm{u}=\mathrm{http} \% 3 \mathrm{~A} \% 2 \mathrm{~F} \% 2 \mathrm{Fphysics}$.gmu.edu $\% 2 \mathrm{~F}-$ hgeller $\% 2 \mathrm{FTeacher}$ Workshop\%2FGuskey2002.pdf\&anno=2>. Acesso em: 2 jul. 2012. 
GUSKEY, Thomas R. Questions \& answers: a conversation with Tohmas R. Guskey. The Evaluation Exchange, Cambridge, v. 11, n. 4, winter 2005. Disponível em: <http://www.hfrp.org/evaluation/the-evaluation-exchange/ issue-archive/professional-development/a-conversation-with-thomas-r.guskey> Acesso em: 2 jul. 2012.

IMBERNÓN, Francisco. La formación pedagógica del docente universitario. Educação, Santa Maria, v. 36, n. 3, p. 387-396, set./dez. 2011.

JUNGES, Kelen dos Santos. Trajetórias de vida, constituição profissional e autonomia de professores. Uniáo da Vitória, PR: Face, 2006.

JUNGES, Kelen dos Santos. Desenvolvimento profissional de professores universitários: caminhos de uma formação pedagógica inovadora. 2013. 221f. Tese (Doutorado em Educação) - Pontifícia Universidade Católica do Paraná, Curitiba, PR, 2013.

LEITE, Denise. Verbetes gerais. In: MOROSINI, Marília C. (Ed.). Enciclopédia da pedagogia universitária: glossário. Brasília: Inep, 2006. v. 2.

LIBÂNEO, José Carlos. Conteúdos, formação de competências cognitivas e ensino com pesquisa: unindo ensino e modos de investigação. In: PIMENTA, Selma Garrido; ALMEIDA, Maria Isabel (Org.). Pedagogia universitária: caminhos para a formação de professores. São Paulo: Cortez, 2011. p. 188-212.

MARCELO GARCÍA, Carlos; VAILLANT, Denise. Desarrollo profesional docente: cómo se aprende a enseñar? Madrid: Narcea, 2009.

MORAN, José Manuel. Ensino e aprendizagem inovadores com tecnologias audiovisuais e telemáticas. In: MORAN, José Manuel; MASETTO, Marcos T.; BEHRENS, Marilda Aparecida. Novas tecnologias e mediação pedagógica. 12. ed. Campinas: Papirus, 2006. p. 11-65.

MORIN, Edgar. Os sete saberes necessários à educação do futuro. 5. ed. São Paulo: Cortez; Brasília: UNESCO, 2002.

NÓVOA, António. Professores: imagens do futuro presente. Lisboa: Educa, 2009. 

de mudança

PIMENTA, Selma Garrido; ANASTASIOU, Léa das Graças Camargo. Docência no Ensino Superior. São Paulo: Cortez, 2002. (Coleção Docência em Formação).

RODRIGUES, Ângela. Análise de práticas e de necessidades de formação. Lisboa: Ministério da Educação, 2006.

RODRÍGUEZ, Pedro S. de Vicente (Dir.). Desarrollo profesional del docente: em um modelo evaluativo de colaboración. Bilbao: Universidad de Deusto, 2002.

ZABALZA, Miguel. O ensino universitário: seu cenário e seus protagonistas. Porto Alegre: Artmed, 2004. 


\section{Práctica docente en la Teaching practice in higher educación superior: la education: pedagogical formación pedagógica como training as a mobilizer of movilizadora de cambio changes}

\section{Resumen}

Se entiende que la formación pedagógica permite al profesor universitario mirar hacia su práctica pedagógica, interpretarla y volver a crearla, tornándola también una fuente de aprendizaje en una perspectiva de cambio y de innovación. Para eso, se optó por presentar en este texto una de las preguntas que formaban una investigación de tesis y tiene como objetivo analizar la formación pedagógica como lo que moviliza el cambio de la práctica docente en la enseñanza superior. La metodología de investigación adoptada es la investigación-acción en un programa de formación pedagógica con profesores de una institución de educación superior pública municipal, llamado Grupo Docencia en Reflexión (GDR). Como instrumento de recolección de datos se utilizó una entrevista semiestructurada con diez de los profesores que participaron del proceso de formación. La categorización de los datos recopilados reveló que los cambios en la práctica pedagógica de los docentes entrevistados, a partir de las actividades del GDR, especialmente orientada en la percepción de ser un profesor universitario, la relación con los estudiantes, la organización didáctica de las clases, la evaluación de proceso de enseńanza y aprendizaje, la práctica reflexiva y las dificultades encontradas

\section{Abstract}

It is understood that pedagogical training allows professors to look at their practice, interpret it and recreate it, as well as making their practices a source of learning in a perspective of change and innovation. For this puspose, we chose to present in this text one of the questions that comprised a research thesis and that aims to analyze the pedagogical training as a way of mobilizing change in the teaching practice in higher education. The research methodology adopted was the action research on an educational program with professors in a higher education public institution, called Grupo Docência em Reflexão - GDR (Teaching Reflection Group). Semi-structured interviews were used as instrument of data collection, with ten teachers participating in the training process. The categorization of the data collected revealed that changes in the pedagogical practice of the teachers interviewed, from the activities of the GDR, especially focused on the perception of being a university professor, on the relationship with students, on the didactic organization of classes, on the evaluation of the teaching and learning process, on the reflective practice and on the difficulties encountered by them to implement some change in their practice. So, it was considered that a proposal 
por ellos para implementar un cambio en su práctica. Así, se consideró que una propuesta de formación pedagógica orientada y compartida de los profesores universitarios, basada en actos reales e inserida en una perspectiva de reflexión, además de un aprendizaje docente más profundo y duradero, moviliza a los cambios en la práctica pedagógica de esos profesores, causando una práctica innovadora.

Palabras claves: Docencia Universitaria. Formación Pedagógica. Práctica Pedagógica. of pedagogical training that is shared and oriented of the university teachers, based on concrete actions and set in a reflexive perspective, besides a more profound and lasting teacher learning, mobilizes changes in the pedagogical practice of these teachers, encouraging an innovative practice

Keywords: University Teaching. Pedagogical Training. Pedagogical Practice.

\section{Kelen dos Santos Junges}

E-mail:kjunges@brturbo.com.br

\section{Marilda Aparecida Behrens}

E-mail:marildaab@gmail.com

Enviado em: 8/3/2014

Aprovado em: 9/12/2014 